\title{
Sintering of Hydroxyapatite/Yttria Stabilized Zirconia Nanocomposites under Nitrogen Gas for Dental Materials
}

\author{
C. H. Leong, ${ }^{1}$ A. Muchtar, ${ }^{1}$ C. Y. Tan, ${ }^{2}$ M. Razali, ${ }^{3}$ and Noor Faeizah Amat ${ }^{1}$ \\ ${ }^{1}$ Department of Mechanical and Materials Engineering, Faculty of Engineering \& Built Environment, \\ Universiti Kebangsaan Malaysia (UKM), 43600 Bangi, Selangor, Malaysia \\ ${ }^{2}$ Department of Mechanical Engineering, Faculty of Engineering, University of Malaya, 50603 Kuala Lumpur, Malaysia \\ ${ }^{3}$ Periodontology Department, Faculty of Dentistry, Universiti Kebangsaan Malaysia, Jalan Raja Muda Abdul Aziz, \\ 50300 Kuala Lumpur, Malaysia \\ Correspondence should be addressed to C. H. Leong; cheehuan@hotmail.my
}

Received 11 August 2014; Revised 11 October 2014; Accepted 25 October 2014; Published 5 November 2014

Academic Editor: Jiangbo Sha

Copyright (c) 2014 C. H. Leong et al. This is an open access article distributed under the Creative Commons Attribution License, which permits unrestricted use, distribution, and reproduction in any medium, provided the original work is properly cited.

\begin{abstract}
This study aims to determine the effect of adding $3 \mathrm{~mol} \%$ yttria stabilized zirconia (3YSZ) in hydroxyapatite (HA) and sintering HA/3YSZ nanocomposites under nitrogen gas on HA decomposition. This paper presents the relationship between microstructure and mechanical properties of HA/3YSZ nanocomposites. Gas pressure and conventional sintering were performed on HA/3YSZ nanocomposites containing different amounts of $3 \mathrm{YSZ}$ (i.e., $0,0.5,1$, and $7 \mathrm{wt} \%$ ) at $1250^{\circ} \mathrm{C}$. The phase stability, morphology, relative density, and microhardness of the HA/3YSZ nanocomposites were investigated. The phase stability of the HA/3YSZ nanocomposites was affected by adding different amounts of 3YSZ. Overall, gas pressure sintering leads to the formation of greater grain size compared with the conventional sintering method. The severe HA decomposition and the presence of the porosity in HA/7 wt\% 3 YSZ have led to deterioration in relative density and microhardness. In this study, HA $/ 0.5 \mathrm{wt} \% 3 \mathrm{YSZ}$ with gas pressure sintering exhibited the optimum microstructure with the highest relative density $(97 \%)$ and microhardness $(3.93 \mathrm{GPa})$.
\end{abstract}

\section{Introduction}

Hydroxyapatite (HA) is biocompatible and osteoconductive, and it exhibits excellent chemical and biological affinity with bone tissues. HA is calcium phosphate that constitutes most of the mineral phase of the bone and tooth enamel. As such, HA has shown great potential as a bioceramic material for human hard tissue implants $[1,2]$. However, the fracture toughness of sintered HA is relatively low $\left(<1 \mathrm{MPam}^{1 / 2}\right)$ compared with the fracture toughness of human bone $\left(2 \mathrm{MPam}^{1 / 2}\right.$ to $12 \mathrm{MPam}^{1 / 2}$ ) [3-5]. The brittleness and the low fracture toughness of sintered HA have limited its capability in load-bearing applications [6-9]. However, the mechanical properties of HA can be improved during its synthesis by adding a second phase into HA [2].

Adding zirconia $\left(\mathrm{ZrO}_{2}\right)$ in $\mathrm{HA}$ improves fatigue resistance and strength compared with $\mathrm{HA}$ alone $[2,10]$. A promising $\mathrm{ZrO}_{2}$ ceramic-containing system in dental healthcare applications is $3 \mathrm{~mol} \%$ yttria stabilized $\mathrm{ZrO}_{2}$ (3YSZ). $3 \mathrm{YSZ}$ is widely used as a dental material because of its good mechanical strength [11]. However, adding $\mathrm{ZrO}_{2}$ decomposes $\mathrm{HA}$ at temperatures lower than/near $1300^{\circ} \mathrm{C}[12,13]$.

HA decomposition is not desirable because this process modifies the physical and chemical properties of HA in biomedical applications [13, 14]. Several factors such as synthesis methods and conditions, amount and type of impurities, heating atmosphere, additives, particle size, sintering temperatures, and heating rate of the samples can modify the HA structure at high temperature $[7,15,16]$. Sintering is the most important step in powder processing used to produce density-controlled materials because it is at this stage that the material is subjected to very high temperature, causing the particles to form bonds that are needed to hold mass together [17]. Sintering methods such as hot isostatic pressing, spark plasma sintering, and microwave sintering have proven that the sintering method has a significant effect on the resulting mechanical strength and microstructure of $\mathrm{HA} / \mathrm{ZrO}_{2}$ composite $[2,18,19]$. Conventional sintering, also known 
as pressureless sintering, is the preferred method in the fabrication of $\mathrm{HA} / \mathrm{ZrO}_{2}$ composites because it is more economical. Conventional sintering indicates sintering in which no external pressure is applied to the body [20]. Among all of the sintering methods that have been studied, near full relative density (99.5\%) with no detectable HA decomposition can be achieved only by the hot isostatic sintering method [19]. However, the fabrication cost for this sintering method is relatively higher than other sintering methods. Undesired interactions between the sintering materials and its surrounding environment at high temperature can be prevented by selecting an appropriate sintering atmosphere. Several possibilities are available in terms of atmosphere selection for sintering of high-performance materials [21]. The objective of the present work is to determine the effect of gas pressure sintering with nitrogen on the microstructure and mechanical strength of hydroxyapatite $/ 3 \mathrm{~mol} \%$ yttria stabilized zirconia (HA/3YSZ) nanocomposites.

\section{Materials and Methods}

The base material for the HA powder used in this study was manufactured by Jinan Boss Chemical Industry Co., Ltd. The size and purity of the HA powder were determined by transmission electron microscopy (TEM) and X-ray diffraction (XRD; Bruker D8). The 3YSZ powder was manufactured by Nabond Nano-Technologies, Shenzhen, China. TEM and energy-dispersive X-ray spectroscopy (EDX) were performed to determine the size and purity of the $3 Y$ SZ powder. HA and 3YSZ powders were mixed by wet ball milling (Fritsch Pulverisette 6) in ethanol at $350 \mathrm{rpm}$ for $1 \mathrm{~h}$. Different compositions of HA/3YSZ were prepared by adding $0,0.5,1$, and $7 \mathrm{wt} \%$ of $3 \mathrm{YSZ}$ in HA. The mixtures were dried in an oven at $60^{\circ} \mathrm{C}$ and then ground into powder using a mortar and pestle. The samples were uniaxially pressed at $50 \mathrm{MPa}$ into pellets. The pellets were then cold isostatically pressed at $200 \mathrm{MPa}$ for $1 \mathrm{~min}$ and sintered using two different methods, namely, conventional and gas pressure sintering by purging nitrogen $\left(\mathrm{N}_{2}\right)$ gas at $1250^{\circ} \mathrm{C}$. The ramp rate of both sintering methods was fixed at $5^{\circ} \mathrm{C} / \mathrm{min}$, and the holding time was $1 \mathrm{~h}$. The $\mathrm{N}_{2}$ gas flow was maintained at approximately $1.5 \mathrm{~L} / \mathrm{min}$ during gas pressure sintering.

The sintered samples were characterized using various tests. The density of the sintered samples was measured by water immersion method (Newclassic MS Mettler Toledo). Field emission scanning electron microscopy (FESEM, Hitachi SU8000) was used to examine the microstructure of the cross section of the sintered samples. XRD was carried out using a Bruker D8 to determine the phases that exist in the sintered samples. The microhardness of the sintered samples was determined by micro indentation method using a Shimadzu HMV-2.

\section{Results and Discussion}

The TEM micrograph of the HA powder is shown in Figure 1. The HA particles were elongated rod-like crystals with a length distribution varying between 106 and $271 \mathrm{~nm}$, whereas the diameter distributions varied between 34 and $48 \mathrm{~nm}$.
TABLE 1: EDX of HA powder.

\begin{tabular}{lcc}
\hline Element & Weight \% & Atomic \% \\
\hline $\mathrm{O}$ & 59.06 & 76.73 \\
$\mathrm{P}$ & 13.35 & 8.96 \\
$\mathrm{Ca}$ & 27.59 & 14.31 \\
\hline
\end{tabular}

TABLE 2: EDX of 3 YSZ powder.

\begin{tabular}{lcc}
\hline Element & Weight $\%$ & Atomic \% \\
\hline $\mathrm{O}$ & 33.15 & 73.86 \\
$\mathrm{Y}$ & 1.63 & 0.65 \\
$\mathrm{Zr}$ & 65.22 & 25.48 \\
\hline
\end{tabular}

Figure 2 shows the TEM micrograph of the 3YSZ powder. The 3YSZ particles had a nanocrystalline structure with spheroidal crystals. Particle size distribution varied between 19 and $48 \mathrm{~nm}$, whereas the average particle size was $34 \mathrm{~nm}$. Crystal agglomeration was visible from the micrograph of both the HA and 3YSZ powders. Agglomeration is the result of the coalescence of secondary particles. When two adjacent primary particles collide, coalescence occurs and the particles combine to form a secondary particle. The small secondary particles continue to collide and coalesce, which may ultimately lead to agglomeration [22, 23]. The crystal agglomeration mechanism is understood to involve consecutive steps of crystal aggregation and molecular growth of aggregates [24]. The smaller the particle size, the higher the surface energy of the materials. Nanomaterials are inherently unstable with high surface energy. Hence, particles will tend to agglomerate to reduce the surface energy to become more stable [25].

The XRD phase analysis of the HA powder is shown in Figure 3. Only hydroxyapatite with the chemical formula of $\mathrm{Ca}_{5}\left(\mathrm{PO}_{4}\right)_{3}(\mathrm{OH})$ matches the peak in the XRD diagram. Table 1 shows the EDX analysis of the HA powder. The EDX results for the HA powder correlate well with the XRD analysis; no impurities can be detected from the EDX analysis of HA powder (Table 1) and 3YSZ powder (Table 2).

The XRD patterns of HA/0.5 wt\% 3YSZ and HA/7 wt $\%$ $3 Y S Z$ using two different sintering atmospheres at $1250^{\circ} \mathrm{C}$ are presented in Figures 4 and 5, respectively. Gas pressure sintering failed to suppress HA decomposition, which occurred in both pressureless sintering and gas pressure sintering methods. However, the amount of 3 YSZ affected HA decomposition. A second phase such as calcium zirconate can be detected from the XRD analysis of HA with the addition of $0.5 \mathrm{wt} \% 3 \mathrm{YSZ}$ under two different sintering atmospheres at $1250{ }^{\circ} \mathrm{C}$. In the HA sample with additional $7 \mathrm{wt} \% 3 \mathrm{YSZ}$, severe HA decomposition occurred as seen by the detection of second phases such as calcium zirconate $\left(\mathrm{CaZrO}_{3}\right)$ and calcium phosphate $\left[\mathrm{Ca}_{3}\left(\mathrm{PO}_{4}\right)_{2}\right]$.

Figures 6 and 7 illustrate the FESEM micrographs of HA/0.5 wt $\% 3$ YSZ fabricated by conventional sintering and gas pressure sintering. Bimodal grain size distribution can be seen from the SEM images of the HA/3YSZ nanocomposites that were sintered using different methods in this study. 


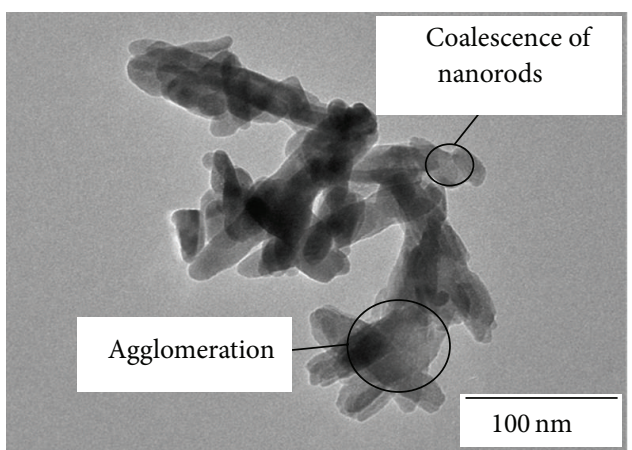

FIGURE 1: TEM micrograph of HA powder.

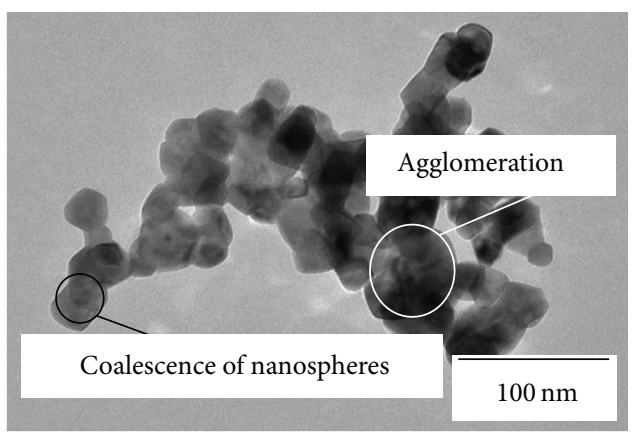

FIGURE 2: TEM micrograph of 3YSZ powder.

Factors such as long sintering time or abnormal grain growth can contribute to bimodal grain size distribution [26]. The grain size of $\mathrm{HA} / 0.5 \mathrm{wt} \% 3 \mathrm{YSZ}$ by conventional sintering varied between $0.3 \mu \mathrm{m}$ and $1 \mu \mathrm{m}$, whereas, for the $\mathrm{HA} / 0.5 \mathrm{wt} \%$ 3 YSZ fabricated by nitrogen sintering, the grain size varied between $0.3 \mu \mathrm{m}$ and $1.7 \mu \mathrm{m}$. A comparison between the two sintering methods shows that gas pressure sintering leads to the formation of bigger grain size.

Figure 8 shows the FE-SEM micrograph of HA containing $7 \mathrm{wt} \% 3 \mathrm{YSZ}$ and subjected to gas pressure sintering. The grain size of HA/3YSZ nanocomposite varied between 0.7 and $1.9 \mu \mathrm{m}$. Figures 9 and 10 show that both HA/7 wt\% 3YSZ and $\mathrm{HA} / 0.5 \mathrm{wt} \% 3 \mathrm{YSZ}$ were sintered under gas pressure. Although the grain size of $\mathrm{HA} / 7 \mathrm{wt} \% 3 \mathrm{YSZ}$ was greater than that of HA/0.5 wt $\%$ 3YSZ, HA/7 wt $\%$ 3YSZ exhibited large pores, with sizes ranging from $0.3 \mu \mathrm{m}$ to $1.1 \mu \mathrm{m}$. On the contrary, HA/0.5 wt\% 3YSZ demonstrated slight porosity. Dehydroxylation within the HA matrix could have contributed to the formation of porous structures [27]. This conclusion is based on the severe decomposition of HA that was observed in the XRD diagram of $\mathrm{HA} / 7 \mathrm{wt} \%$ 3YSZ. Figure 9 shows the average grain size of HA containing different amounts of 3YSZ. HA/0.5 wt $\%$ 3YSZ showed the highest average grain size $(0.74 \mu \mathrm{m})$, whereas HA/7 wt $\%$ exhibited the lowest average grain size $(0.69 \mu \mathrm{m})$. These results agree with the size range of the grain size and mechanical properties of the samples.

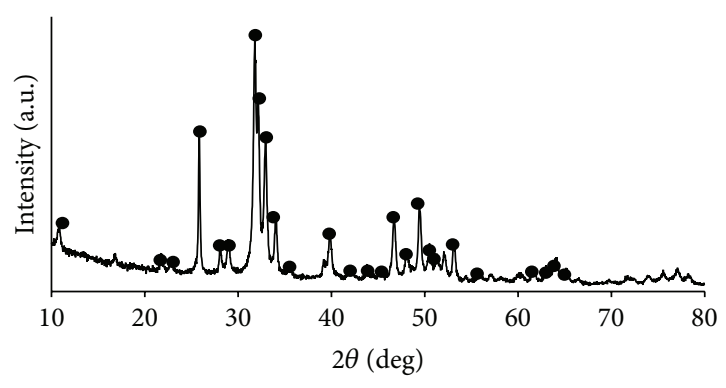

- Hydroxyapatite, $\mathrm{Ca}_{5}\left(\mathrm{PO}_{4}\right)_{3}(\mathrm{OH})$ (01-071-1731)

FIGURE 3: XRD pattern of HA powder.

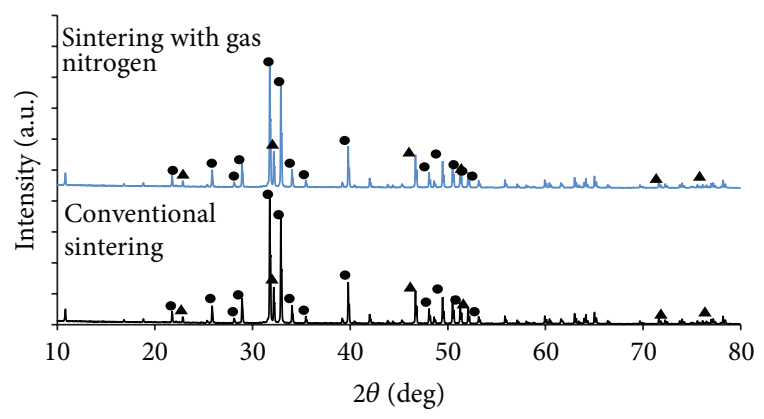

- Hydroxyapatite, $\mathrm{Ca}_{5}\left(\mathrm{PO}_{4}\right)_{3}(\mathrm{OH}) ;(01-071-1731)$

\ Calcium zirconium oxide, $\mathrm{CaZrO}_{3} ;(00-035-0645)$

FIGURE 4: XRD patterns of HA with the addition of $0.5 \mathrm{wt} \% 3 \mathrm{YSZ}$ under two different sintering atmospheres at $1250^{\circ} \mathrm{C}$.

Figure 10 shows the relative density of the HA/3YSZ nanocomposites sintered using two different methods. Overall, the HA/3YSZ nanocomposites subjected to gas pressure sintering showed improved relative density compared to those subjected to conventional sintering. The product containing $0.5 \mathrm{wt} \% 3 \mathrm{YSZ}$ in $\mathrm{HA}$ and sintered in $\mathrm{N}_{2}$ exhibited the highest relative density (97\%). The relative density of the HA/3YSZ nanocomposites subjected to conventional sintering increased with increasing amount of added 3YSZ up to $1 \mathrm{wt} \%$. The relation between grain size and relative density has been investigated in earlier works, and results show that the relative density of pure alumina and yttria increases with increasing grain size $[17,28]$. Pores may be eliminated from the grain boundaries and become trapped in the grain when the grain size increases [29]. Adding $7 \mathrm{wt} \% 3 \mathrm{YSZ}$ decreased the relative density of the HA/3YSZ nanocomposites. Calcium phosphate and calcium zirconate are the byproducts of the HA decomposition [18]. The presence of low-density calcium phosphate [30] in HA added with $7 \mathrm{wt} \% 3 \mathrm{YSZ}$ caused a decrease in the density of HA/3YSZ nanocomposites. The presence of porosity also decreased the relative density of the sample containing $7 \mathrm{wt} \% 3 \mathrm{YSZ}$.

The hardness of the HA/3YSZ nanocomposites that were prepared using two different sintering methods is shown in Figure 11. The application of gas pressure sintering resulted in higher hardness than the conventional sintering method. The highest microhardness obtained from this study is $3.93 \mathrm{GPa}$ 


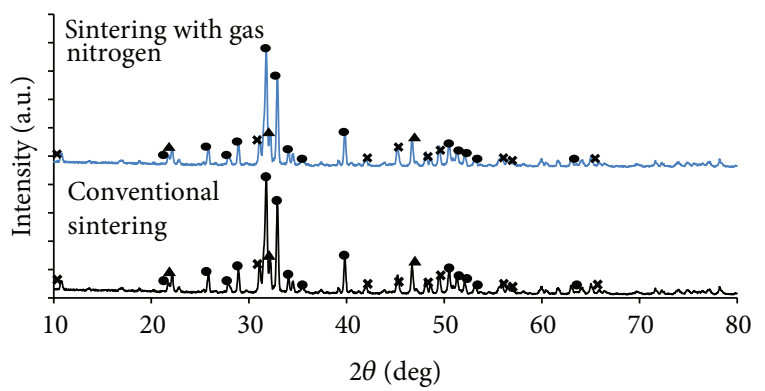

- Hydroxyapatite, $\mathrm{Ca}_{5}\left(\mathrm{PO}_{4}\right)_{3}(\mathrm{OH}) ;(01-071-1731)$

\ Calcium zirconium oxide, $\mathrm{CaZrO}_{3} ;(00-035-0645)$

× Calcium phosphate, $\mathrm{Ca}_{3}\left(\mathrm{PO}_{4}\right)_{2} ;$ (01-086-1585)

FIGURE 5: XRD patterns of HA with the addition of $7 \mathrm{wt} \% 3 \mathrm{YSZ}$ under two different sintering atmospheres at $1250^{\circ} \mathrm{C}$.

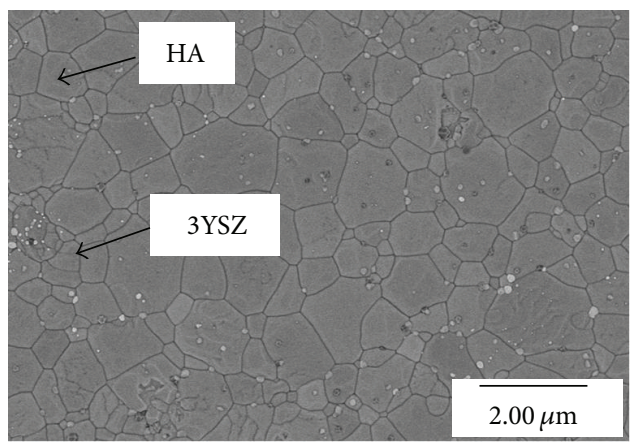

FIGURE 6: FESEM image of HA/0.5 wt\% 3YSZ with conventional sintering.

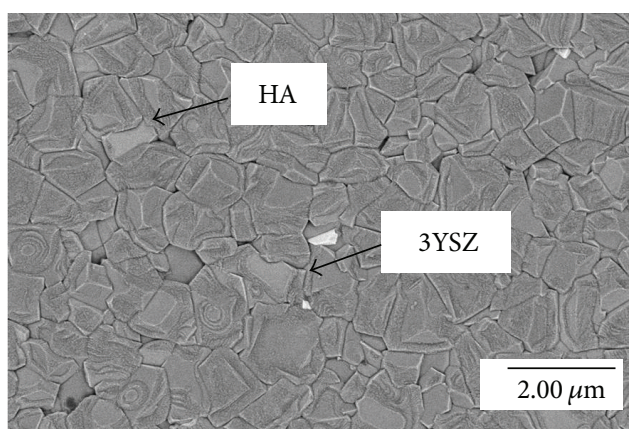

FIGURE 7: FESEM image of HA/0.5 wt\% 3YSZ with nitrogen sintering.

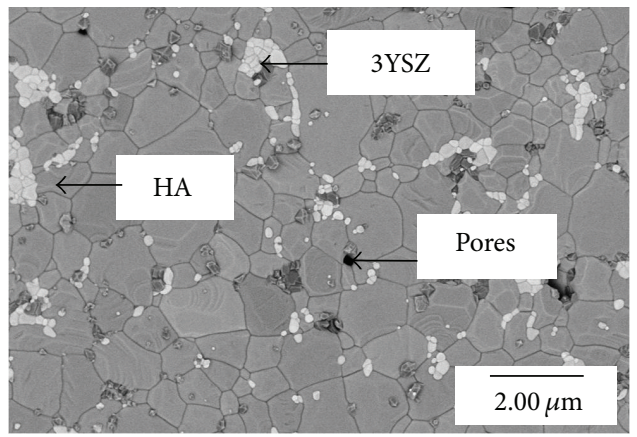

FIGURE 8: FESEM image of HA/7 wt\% 3YSZ with nitrogen sintering.

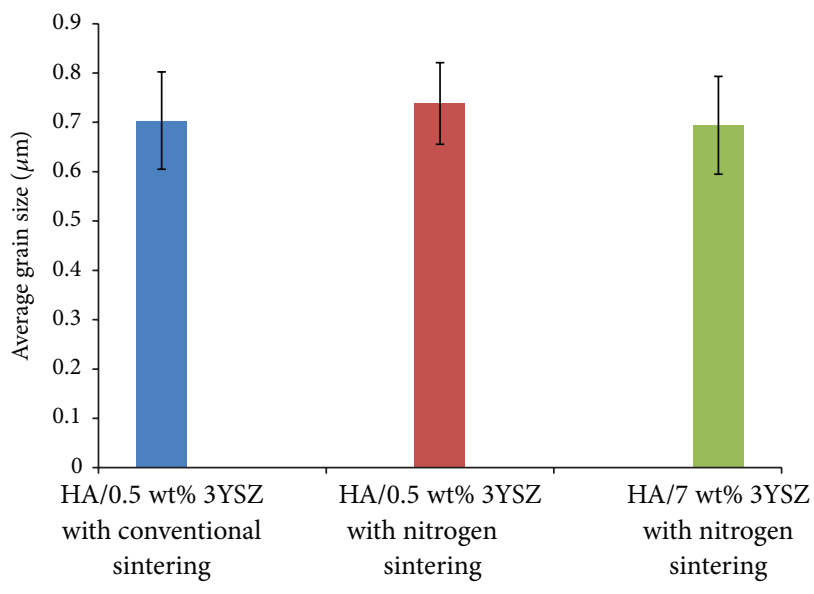

FIGURE 9: Average grain size of HA containing different amounts of 3 YSZ.

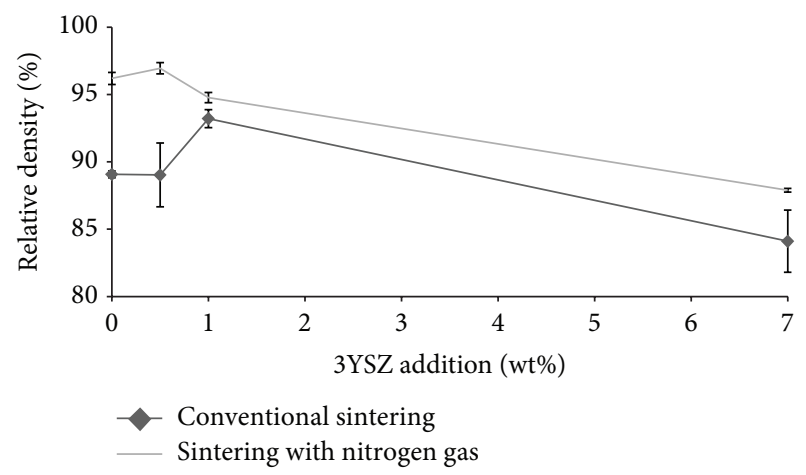

FIGURE 10: Relative density of HA/3YSZ nanocomposites using different sintering methods.

from the HA with the $0.5 \mathrm{wt} \%$ addition of $3 \mathrm{YSZ}$ using the gas pressure sintering method. In this study, HA with the $7 \mathrm{wt} \%$ addition of $3 \mathrm{YSZ}$ using conventional sintering shows the lowest microhardness value (1.32 GPa). This is due to the presence of calcium zirconate and calcium phosphate upon decomposition of the HA with $7 \mathrm{wt} \%$ of 3YSZ [31]. Porosity exhibited by HA containing $7 \mathrm{wt} \% 3 \mathrm{YSZ}$ also decreased the hardness of the nanocomposite.

The effect of the sintering method on the density, microhardness, and microstructure is clearly observed in this study. Gas pressure sintering results in higher density, higher microhardness, and larger grain size with fewer pores than the conventional sintering method.

\section{Conclusion}

HA/3YSZ nanocomposites were successfully prepared by wet ball milling and sintered under two different conditions, one being pressureless sintering and the other pressure sintering using nitrogen gas. However, HA decomposition was found to take place in the samples regardless of the sintering methods. The XRD analysis of the HA/3YSZ nanocomposites that were sintered under both atmospheres exhibited peaks 


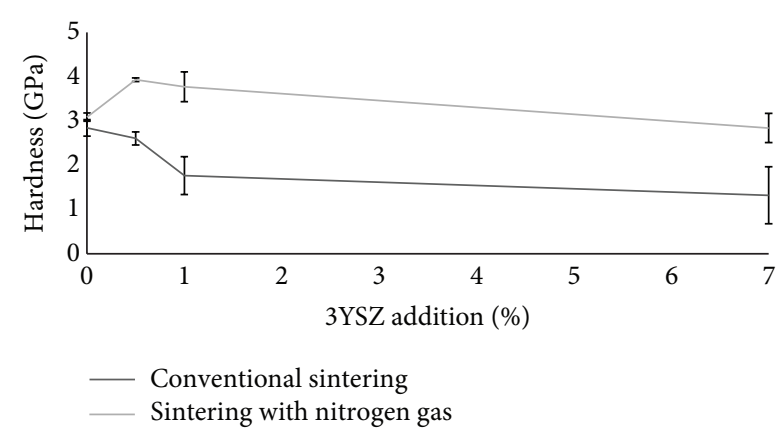

FIgURE 11: Hardness of HA/3YSZ nanocomposites prepared using two different sintering methods.

that correspond to the formation of second phases such as calcium zirconate and calcium phosphate. The HA added with $0.5 \mathrm{wt} \% 3 \mathrm{YSZ}$ that was sintered with gas nitrogen exhibits the optimum relative density and microhardness with larger grain size. The formation of porosity in the sample with high percent of 3YSZ addition (7 wt\%) in HA has led to the reduction in relative density, as well as microhardness. Overall, the application of gas pressure sintering on the HA/3YSZ nanocomposites shows larger grain size, better microhardness, and higher relative density than conventional sintering method.

\section{Conflict of Interests}

The authors declare that there is no conflict of interests regarding the publication of this paper.

\section{Acknowledgment}

The authors acknowledge the sponsorship granted by the Universiti Kebangsaan Malaysia under the UKM-AP-NBT14-2010 and FRGS/1/2013/SG06/UKM/01/1.

\section{References}

[1] H. R. Ramay and M. Zhang, "Preparation of porous hydroxyapatite scaffolds by combination of the gel-casting and polymer sponge methods," Biomaterials, vol. 24, no. 19, pp. 3293-3302, 2003.

[2] X. Miao, Y. Chen, H. Guo, and K. A. Khor, "Spark plasma sintered hydroxyapatite-yttria stabilized zirconia composites," Ceramics International, vol. 30, no. 7, pp. 1793-1796, 2004.

[3] W. Suchanek and M. Yoshimura, "Processing and properties of hydroxyapatite-based biomaterials for use as hard tissue replacement implants," Journal of Materials Research, vol. 13, no. 1, pp. 94-117, 1998.

[4] I. H. Arita, D. S. Wilkinson, M. A. Mondragón, and V. M. Castaño, "Chemistry and sintering behaviour of thin hydroxyapatite ceramics with controlled porosity," Biomaterials, vol. 16, no. 5, pp. 403-408, 1995.

[5] G. Muralithran and S. Ramesh, "The effects of sintering temperature on the properties of hydroxyapatite," Ceramics International, vol. 26, no. 2, pp. 221-230, 2000.
[6] W. Siswomihardjo, S. Sunarintyas, and A. E. Tontowi, "The effect of zirconia in hydroxyapatite on Staphylococcus epidermidis growth," International Journal of Biomaterials, vol. 2012, Article ID 432372, 4 pages, 2012.

[7] S. Ramesh, C. Y. Tan, I. Sopyan, M. Hamdi, and W. D. Teng, "Consolidation of nanocrystalline hydroxyapatite powder," Science and Technology of Advanced Materials, vol. 8, no. 1-2, pp. 124-130, 2007.

[8] V. V. Silva and F. S. Lameiras, "Synthesis and characterization of composite powders of partially stabilized zirconia and hydroxyapatite," Materials Characterization, vol. 45, no. 1, pp. 51-59, 2000.

[9] M. A. F. Afzal, P. Kesarwani, K. M. Reddy, S. Kalmodia, B. Basu, and K. Balani, "Functionally graded hydroxyapatite-aluminazirconia biocomposite: Synergy of toughness and biocompatibility," Materials Science and Engineering C, vol. 32, no. 5, pp. 1164-1173, 2012.

[10] E. Chang, W. J. Chang, B. C. Wang, and C. Y. Yang, "Plasma spraying of zirconia-reinforced hydroxyapatite composite coatings on titanium Part I Phase, microstructure and bonding strength," Journal of Materials Science: Materials in Medicine, vol. 8, no. 4, pp. 193-200, 1997.

[11] N. R. F. A. Silva, I. Sailer, Y. Zhang et al., "Performance of zirconia for dental healthcare," Materials, vol. 3, no. 2, pp. 863896, 2010.

[12] Z. Evis, M. Usta, and I. Kutbay, "Improvement in sinterability and phase stability of hydroxyapatite and partially stabilized zirconia composites," Journal of the European Ceramic Society, vol. 29, no. 4, pp. 621-628, 2009.

[13] A. Rapacz-Kmita, A. Ślósarczyk, Z. Paszkiewicz, and C. Paluszkiewicz, "Phase stability of hydroxyapatite-zirconia ( $\mathrm{HAp}-\mathrm{ZrO}_{2}$ ) composites for bone replacement," Journal of Molecular Structure, vol. 704, no. 1-3, pp. 333-340, 2004.

[14] P. Parente, B. Savoini, B. Ferrari, M. A. Monge, R. Pareja, and A. J. Sanchez-Herencia, "Effect of highly dispersed yttria addition on thermal stability of hydroxyapatite," Materials Science and Engineering C, vol. 33, no. 2, pp. 864-869, 2013.

[15] C.-J. Liao, F.-H. Lin, K.-S. Chen, and J.-S. Sun, "Thermal decomposition and reconstitution of hydroxyapatite in air atmosphere," Biomaterials, vol. 20, no. 19, pp. 1807-1813, 1999.

[16] S. Ramesh, C. Y. Tan, R. Tolouei et al., "Sintering behavior of hydroxyapatite prepared from different routes," Materials \& Design, vol. 34, pp. 148-154, 2012.

[17] G. Bernard-Granger, N. Monchalin, and C. Guizard, "Sintering of ceramic powders: determination of the densification and grain growth mechanisms from the "grain size/relative density" trajectory," Scripta Materialia, vol. 57, no. 2, pp. 137-140, 2007.

[18] D. Curran, T. J. Fleming, M. R. Towler, and S. Hampshire, "Mechanical properties of hydroxyapatite-zirconia compacts sintered by two different sintering methods," Journal of Materials Science: Materials in Medicine, vol. 21, no. 4, pp. 1109-1120, 2010.

[19] C. Ergun, "Enhanced phase stability in hydroxylapatite/zirconia composites with hot isostatic pressing," Ceramics International, vol. 37, no. 3, pp. 935-942, 2011.

[20] M. N. Rahaman, Ceramic Processing and Sintering, Taylor \& Francis, 2003.

[21] Z. Z. Fang, Sintering of Advanced Materials Fundamentals and Processes, Woodhead, Philadelphia, Pa, USA, 2010.

[22] B. Akbari, M. P. Tavandashti, and M. Zandrahimi, "Particle size characterization of nanoparticles-a practical approach," 
Iranian Journal of Materials Science and Engineering, vol. 8, no. 2, pp. 48-56, 2011.

[23] A. Fahami, B. Nasiri-Tabrizi, and R. Ebrahimi-Kahrizsangi, "Synthesis of calcium phosphate-based composite nanopowders by mechanochemical process and subsequent thermal treatment," Ceramics International, vol. 38, no. 8, pp. 6729-6738, 2012.

[24] J. M. Kim, S. M. Chang, K. S. Kim, M. K. Chung, and W. S. Kim, "Acoustic influence on aggregation and agglomeration of crystals in reaction crystallization of cerium carbonate," Colloids and Surfaces A: Physicochemical and Engineering Aspects, vol. 375, no. 1-3, pp. 193-199, 2011.

[25] N. Mandzy, E. Grulke, and T. Druffel, "Breakage of $\mathrm{TiO}_{2}$ agglomerates in electrostatically stabilized aqueous dispersions," Powder Technology, vol. 160, no. 2, pp. 121-126, 2005.

[26] R. Donald and P. P. Askeland, The Science and Engineering of Materials, International Students, 2006.

[27] I. Sopyan, S. Ramesh, N. A. Nawawi, A. Tampieri, and S. Sprio, "Effects of manganese doping on properties of sol-gel derived biphasic calcium phosphate ceramics," Ceramics International, vol. 37, no. 8, pp. 3703-3715, 2011.

[28] N. F. Amat, A. Muchtar, M. J. Ghazali, and N. Yahaya, "Suspension stability and sintering influence on yttria-stabilized zirconia fabricated by colloidal processing," Ceramics International, vol. 40, no. 4, pp. 5413-5419, 2014.

[29] H. Kim, Low Temperature Sintering of Nanosized Ceramic Powder: YSZ-Bismuth Oxide System, The Ohio State University, 2004.

[30] K. A. Khalil, S. W. Kim, and H. Y. Kim, "Consolidation and mechanical properties of nanostructured hydroxyapatite$\left(\mathrm{ZrO}_{2}+3 \mathrm{~mol} \% \mathrm{Y}_{2} \mathrm{O}_{3}\right)$ bioceramics by high-frequency induction heat sintering," Materials Science and Engineering A, vol. 456, no. 1-2, pp. 368-372, 2007.

[31] M. R. Towler and I. R. Gibson, "The effect of low levels of zirconia addition on the mechanical properties of hydroxyapatite," Journal of Materials Science Letters, vol. 20, no. 18, pp. 1719-1722, 2001. 

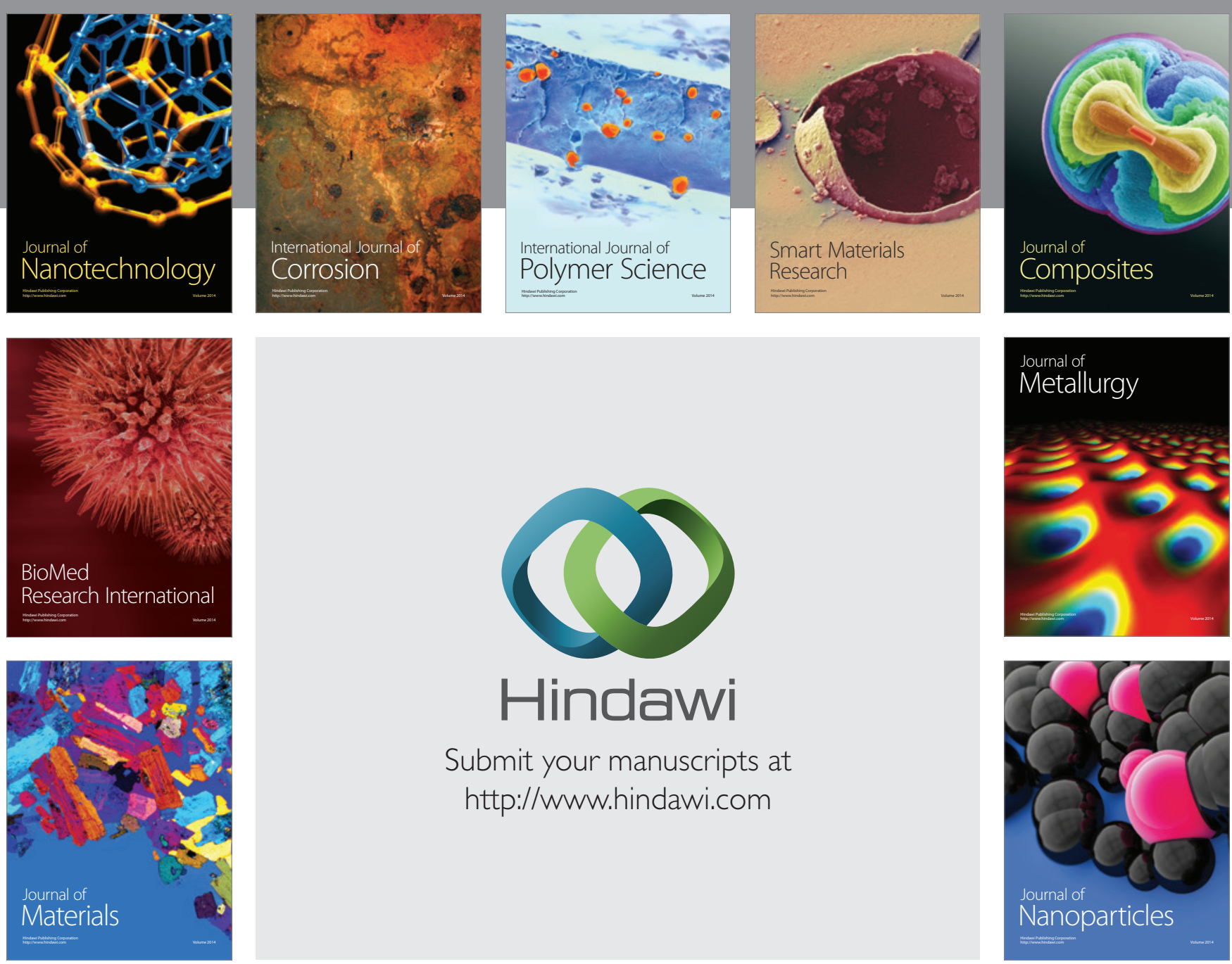

Submit your manuscripts at http://www.hindawi.com
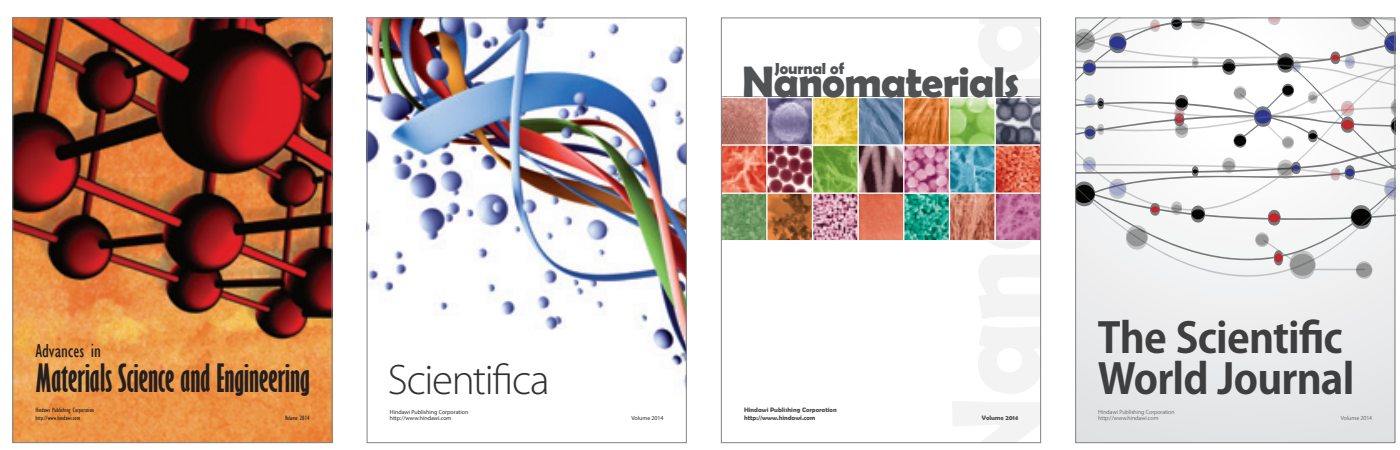

\section{The Scientific World Journal}
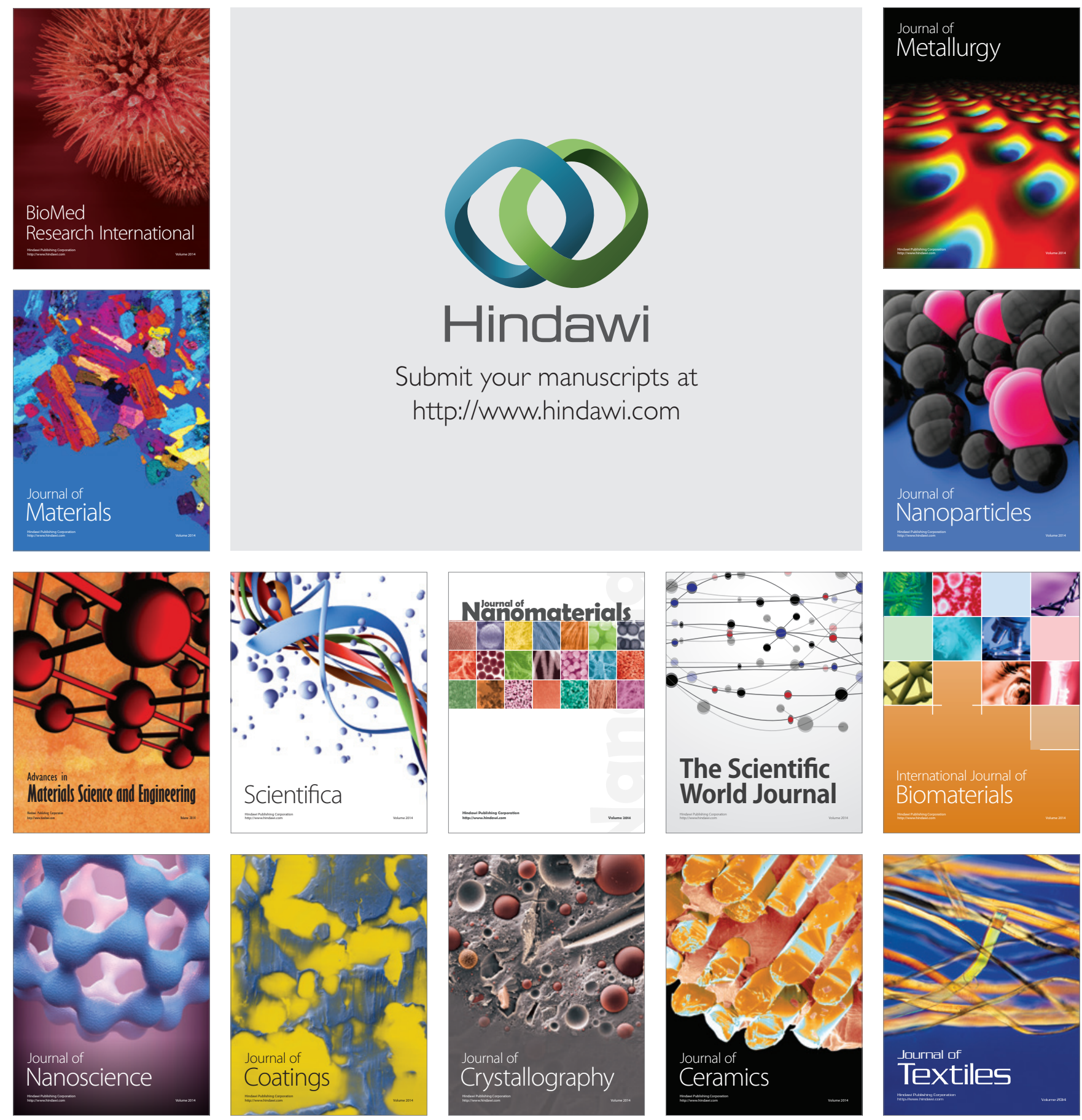